\title{
COVID19 Non-compliance; Maslow's Theory of Needs and the Human Spirit: Are they Linked?
}

\section{Manfred Mortell RN*}

Assistant Professor Nursing, Department of Nursing, University of the Bahamas, Nassau, Bahamas

*Corresponding Author: Manfred Mortell RN, Assistant Professor Nursing, Department of Nursing, University of the Bahamas, Nassau, Bahamas.
Received: November 17, 2021

Published: January 27, 2022

(C) All rights are reserved by Manfred Mortell RN.

\begin{abstract}
The coronavirus disease 2019 (COVID-19) began in Wuhan, China in 2019. The COVID-19 pandemic incarnates a significant worldwide health emergency, with international governments endorsing COVID-19 safeguard actions; which necessitated a noteworthy change in public behavior. However, non-compliance with safeguard processes, such as the "lockdown", social and physical distancing, hand-hygiene conformity, and the use of personal protective equipment, such as facemasks were prevalent. Distinguishing and comprehension of the structure of human needs was crucial for the operational preparation and implementation of COVID-19 safety strategies. In order to increase community compliance with COVID-19 pandemic safeguards, reducing defiant behaviors, and protecting lives, Abraham Maslow's theory of human needs could explain public non-compliance behavior. Maslow's theory of human needs proposes a structure which illuminates why human beings are motivated, how they thrive, and why they may become non-compliant with COVID19 safety guidelines which are employed as safety measures.
\end{abstract}

Keywords: Behavior; COVID-19; Maslow's Theory of Human Needs; Non-compliance

\section{Introduction}

In previous pandemics, there were members in every community that were recognized as being non-compliant, in regard to municipal health processes intended at limiting the spread of infectious diseases such as COVID-19 [1]. Thus, the likelihood of spreading the disease was much greater [1]. Identifying the human needs to generate compliance is therefore a decisive pandemic strategy. Socio-demographic needs are often revealed in an individual's behavior, as are their response levels, whether positive or negative.

[2]. Maslow's hierarchy of needs provides a structure for understanding these needs, the reasoning that influences society in times of misfortune, and what influences us as human beings [3].

\section{Background}

Maslow's theory of needs is a theory that segregated human motivations into a five level pyramid known as Maslow's Hierarchy of Needs [3]. The lowest level is acknowledged as the "physiological needs", which include air, food, water, warmth, rest and sleep. He suggested that without these basic needs, the human body cannot operate effectively physiologically. The second level, are "safety needs", which involves a need for security, as they represent control and order in a person's life. This need can be achieved through social stability. "Belongingness and love" is the third need level and refers to interpersonal relationships; such as being loved, accepted, and intimacy. "Esteem" needs are the fourth level and included self-esteem, and prestige, which involved respect or status from colleagues, contemporaries, friends and other members of society. The final level was "Self-actualization" and was the highest level and signified that a person had achieved their goals in life. The "physiological needs" are therefore the basis of the hierarchy of needs, the more the physiological needs are satisfied, the more a person will attempt to satisfy their safety and security needs [4]. During the COVID-19 pandemic, worldwide governments sanc- 
tioned "lockdowns" and subsequently disturbed the basic level of physiological needs. Needs such as access to food, water and rest, affected a person's safety and security needs, such as employment and means, which in the long term involved their motivation to accomplish the subsequent levels of needs related to social, esteem, and self-actualization.

The novel SARS-CoV-2 virus driving the present pandemic is not unlike the four "common cold" coronavirus variants that have marked local and global populations; causing societies to suffer temperate respiratory tract illnesses [5]. Coronaviruses are a class of viruses that can initiate a variety of conditions such as the common cold, an upper respiratory tract infection, and severe acute respiratory syndrome and Middle East respiratory syndrome. The novel coronavirus disease, 2019 (COVID-19) epidemic began in Wuhan, China, in December 2019. COVID-19 symptoms can range from being mild, moderate to critical with some individuals being asymptomatic, while others who are older or who have preexisting comorbidities such as cardiovascular disorders, chronic pulmonary disease, diabetes mellitus, are potentially at greater risk $[6,7]$. On January $30^{\text {th }} 2020$, the WHO declared a public health emergency of international proportions and requested a communal effort from all nations to prevent the rapid spread of COVID-19 [8]. Public health organizations such as the Center for Diseases and control (CDC), and the WHO, monitored the pandemic and issued safeguard recommendations to prevent and manage the disease. Thus, it was essential that the worldwide community obey the generic safety guidelines to prevent the spread of the COVID-19 virus. However, people's adherence to the recommended lockdown and mandated control measures were disobeyed, which repeatedly became a concern. In 1987 the CDC issued a Universal Precautions Policy which founded blood and body fluid safeguards. In the context of the current COVID-19 pandemic, unparalleled processes were employed to control the spread of the COVID-19 virus. The fear of the COVID-19 pandemic infiltrated all global communities which marked the psychological, physical, social, financial, learning and safety aspects related to a human being's normal life. The COVID-19 pandemic required the public to accept a "new normal", which required people to work from home and the use personal protective equipment (PPE) in an effort to thwart this potentially fatal disease. The WHO, [9] also recommended universal precautions such as hand hygiene, avoiding the touching of the eyes, nose and mouth, maintaining social distancing, the practice of respira- tory etiquette, and seeking medical treatment if unwell. The "new normal" was endorsed by international governments, which included the termination of public gatherings for educational and religious institutions, restaurants, clubs, cinemas, theatres, parks, and public transportation systems. People were therefore required to remain inside their homes, maintain social distancing and accept universal precautionary measures [5].

\section{COVID-19 Non-compliance}

In the past, infectious diseases have been responsible for the greatest number of human deaths, for example, the bubonic plague decimated about $25 \%$ of the European population [10]. The $1^{\text {st }}$ pandemic outbreak of the bubonic plague was in the 1500s; with a $2^{\text {nd }}$ pandemic that occurred in France, Italy, Holland and England killing in excess of two and a half million people between 1600 and 1670 [11]. Occurrences of bubonic plague also commenced in Southern China in 1865, and between 1894 and 1929 there were over 24,000 cases in Hong Kong, which were spread to India, where over twelve million people perished [12] The people at greatest risk from COVID-19 are the elderly and individuals with serious underlying medical disorders [13]. According to the CDC, older adults at risk of serious complications are those aged 65 years and above with comorbidities such as diabetes mellitus; liver disease; chronic lung disease, asthma; heart conditions; immune system deficits. The uncertainties that have arisen during this pandemic are whether people realize the mode in which the coronavirus is spread, the risk that it imposes; the notion of universal precautions, the correct use of facemasks, and the compliance required for safety guidelines. In March 2020, the WHO announced an exceptional request to the community for increased compliance with public health procedures which were intended to control the spread of COVID-19. This plea was for everyone, but notably intended for young adults who have been recognized globally as being noncompliant, and are often defiant in regard to public health measures aimed at curbing the spread of COVID-19 [1]. Young adults frequently exhibited mild or no symptoms of COVID-19, while being infectious. Therefore, the potential for dissemination of the virus was contemplated to be greater than what is typical, considering that these members of the community foster sizeable social structures due to lively social lives [1]. For that reason, Maslow's theory of human needs has noteworthy relevance and should be studied in the context of non-compliance with safety guidelines for 
COVID-19., Physiological needs, safety needs, social needs, esteem needs, and self-actualization may illuminate why people risk their lives, their families lives, and the lives of community by disregarding the nature of coronavirus with defiant behaviors.

\section{COVID-19 Non-compliance and Maslow's hierarchy of needs}

In Maslow's hierarchy of needs [Figure 1], physiological needs are fundamental for the survival of an individual. In the background of the COVID-19 pandemic, these needs correlate with the second level which combines safety and security needs. These fundamental needs typically occur in situations of shortage which generates feelings of anxiety and stress in people [3]. The emotion associated with concern can be attributed to credence that people in the community might reason that without fundamental needs such as food, water, imposed during a lockdown, that this could affect their life significantly and much faster than the effects associated with the COVID-19 virus. Conspicuous examples of this reasoning occurred globally, was the panic buying and stockpiling of needless amounts of grocery items such as toilet paper. The stockpiling of such items by the global community underlines the evident fear about their availability. To acquire these fundamentals, people were often noncompliant with authorized safety guidelines such as accurate use of facemasks, social distancing to elude crowded facilities and to ensure ample ventilation. When exiting their homes to obtain grocery items, non-compliant offenders endangered not only their lives, but their families, the front liners, and the community. The logic for non-compliance was to secure and satisfy fundamental needs. Therefore, a rational assumption according to Maslow, (1943) would be to assume that people must gratify their basic needs, irrespective of the consequences related with the COVID-19 virus.

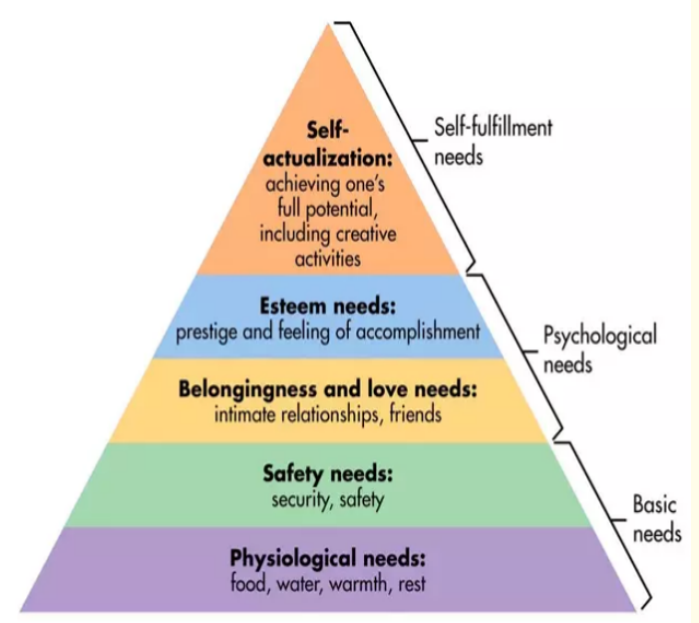

Figure 1: Maslow's Hierarchy of Needs.
The second physiological need which Abraham Maslow advocated was the need of safety, which in the case of COVID-19 can be signified as the motivation to feel protected in a safe environment. It incorporates a need for effective hand hygiene, disinfectants, use of facemasks, social distancing, ensuring effective ventilation and lockdown self quarantine if instructed. However, despite the fears linked to the COVID-19 virus, the general public continued to interact socially in groups, despite being illegal. Regardless of the social distancing and lockdown instructions, people were often non-compliant, and confirmed that human survival requires interaction with other humans; in essence underpinning what makes us human beings. Human beings subsist in groups whether they are diminutive like a family or sizeable like a city or a country. Human beings are social animals and therefore human beings cannot and do not live in isolation [14]. In the setting of COVID-19, noncompliance behavior and Maslow's third level; belongingness and love needs, social contact appears to be necessary for people in the community, because they have loved ones they care about. However, non-compliance behaviors related to psychological needs during the pandemic were often diminished by online internet tools, such as WhatsApp, Zoom, Facebook, and Google meet to name a few. These virtual communication tools allowed people to stay in social contact with family, business and members of their community. Regular communication via online internet agents offered a psychological resource of support to get away from feelings of loneliness, perceived abandonment, anxiety, stress and fear. The needs related to level 3, belonging, love and human interaction [3], whether with family, friends or the community, lowered anxiety and fear in these unprecedented times. It ought to be mentioned that social contact is also important for a person's mental health [14], as it reduces stress which occur in major life changes like the "new normal" phenomenon. Realizing that we as human beings are loved and valued by others is an important mental element that supports people to adjust to adverse facets of their current COVID-19 lives, and assist people to be more positive about their future. Another consideration in respect to community non-compliance with lockdown strategies is the convincing evidence that proposes that human contact is also vital for physical health in human beings [15]. The association that is linked with the significance of diminished human interaction is a multitude of co-morbidities which includes cardiovascular disease, autoimmune disorders, and cancer [15]. As an individual traverses Maslow's hierarchy of needs, the fourth level esteem needs, relates to prestige, accomplishment and selfassurance. Individuals who accomplish this need cultivate satisfaction, recognition and acquire status. In the setting of the COVID-19 pandemic, a person's self-assurance and beliefs provides under- 
standings, about the virus and could have been the motivation and justification for their COVID-19 non-compliance. Regrettably, community support of non-compliance for safety guidelines could also have encouraged defiant behavior. Once individuals have achieved both the basic and psychological needs, they would be encouraged to achieve and reach the final level, that of self-fulfillment, the highest level, self-actualization. This need is located at the pinnacle of Maslow's hierarchy of needs; and in the setting of the COVID-19 pandemic could represent a front liner's or just a normal person's need to assist and support the community. The highest level of selfactualization is typically associated with the altruistic people [3] who put themselves at risk, risking their life to provide care for those people who could or have become afflicted with the COVID-19 virus. Examples would include the care services provided by front line workers, such as health care professionals and providers, physicians and surgeons, police officers and the military. According to Maslow (1943) within such labors and endeavors, these individuals display the attainment of the highest level of human needs; that of self-actualization.

\section{Discussion}

During a pandemic such as COVID-19 a central emotional response for defying biological threats is fear [16]. Unwanted emotions are challenging and result from an unsafe situation which can be infectious, for the reason that fear can make fears appear more frightening [17]. Fear often creates a change in a person's behavior, if they feel incapable of dealing with the dangers, this would result in a self-protective action [14]. Fear responses associated with a positive attitude produce beneficial behaviors, such as "compliance" whereas fear reactions associated with a negative attitude produce self-justifying defending responses, which could correlate to "non-compliance" [14]. An additional trial is that people often display an "optimism bias" which is a trust that unpleasant things are less likely to occur to one-self compared to others. While optimism bias may be useful to avoid negative emotions, it can make people misjudge events such as the likelihood of contracting a disease such as COVID-19 and to be non-compliant.

There is also a shared belief that when feeling vulnerable, people panic, that is to say, they act instinctively for self - preservation, and in doing so possibly put in danger the entire group [15]. This view could explain community consequences in relation to the motivation for 'panic buying' which befell in the current COVID-19 pandemic. Unquestionably, there are people in the community who act with self-interest as their priority; for example, the global "toilet paper" farce. But collaboration and disciplined behavior is also shared across a span of adversities; and there are a myriad of noteworthy altruism examples from people in the global community [18]. One significant altruistic factor that has emerged is a sense of a communal identity and concern for others, which does arise from the shared experience of being in danger. This feeling can be directed by requesting that the public in communal terms to take action for the common good of the community, as occurred with the WHO request in March, 2020. Conversely, the sense of a communal identity can be challenged by inferring members of the community are seen as the adversaries. This occurs when News reports state and show images of public chaos, panic buying, stock piling of supplies and the empty super-market shelves. These reports often imply that people who panic buy are self-centered, self-seeking, egocentric and selfish [19]. News stories that report this notion of panic; especially in times of crisis such as the COVID-19 pandemic, often create the very fear phenomena that they claim to reprimand.

An individual's behavior; is often influenced by community values that reflect either approval or disapproval, and can also be influenced by standards, often called "norms" For example, people can undervalue the importance of health advocating behaviors such as compliance with hand hygiene [20] or underestimate harmful behaviors [21] such as non-compliance with hand hygiene. Achieving compliant behaviors during a pandemic such as COVID-19 can often be accomplished by providing constructive information, such as clear, evidence based instructions. However; accurate information about the health safety proceedings must also be endorsed by people in the community who approve of these actions [22]. Identified "norms" are most persuasive when identifiable to others with whom common characteristics are shared [23] such as compliance with safety health behaviors [24]. Social networks such as family and friends of family can also increase compliance or non-compliance of behaviors which can be detrimental or favorable during a situation such as a pandemic [25]. The COVID-19 virus is transmitted from person to person, and since people demand social group interaction, they are more likely to come into contact with other people, and are subsequently among the first to be infected [26].

COVID-19 is a somewhat new virus that has had devastating global consequences since it was first detected in Wuhan, China 
in 2019. To date, there has been limited published research data on why some members of the community continue to be noncompliant with COVID-19 safety guidelines. In the circumstance of Maslow's hierarchy of needs, the uniqueness and uncertainties of this contagious disease make it essential for health authorities to devise appropriate strategies to prepare and manage public noncompliance in the future. Comprehension of Maslow's hierarchy of needs may clarify why some members of the community continue to be non-compliant with safety guidelines that are intended to reduce transmission and save lives. Utilizing Maslow's hierarchy of needs may "shed light" on community non-compliance behaviors with the safety guidelines, especially since health authorities have been consistently disseminating COVID-19 information ever since the disease was first detected. From the time the COVID-19 pandemic began in 2019, global life has transformed radically to what we now call the "new normal". During a "lockdown" or movement control order, everything we took for granted, such as visiting family, family gatherings, seeing friends, going to religious services or going to work was either stopped or modified in some manner and we as a community, local or global were told to stay at home. The consequence of the "new normal" created by the COVID-19 pandemic has provided an opportunity for a renewed application and interpretation of Maslow's Hierarchy of Needs. Physiological needs have had a substantial impact on all nations, as the need for basics such as food and groceries were often experienced globally. Supermarkets and stores just couldn't keep up with overwhelming community demands. Items such as "toilet paper", flour, eggs, rice and pasta were insufficient and shopping became a consumer challenge, contest and a nightmare. Sleep and rest also became problematic for many people, which were expected in times of adversity as everyday routines were involved and altered. When the first level of basic needs was disrupted at the commencement of the pandemic, it was challenging for people, but when the second level, safety needs was also involved, life became to a certain extent harder and more distressing. The need for safety and security was driven to the limit, as individuals and groups in the community were concerned about the economic climate, personal finances and their employment security. Safety and security issues of concern involved the community non- compliance of authorized safety guidelines; such as employing hand hygiene effectively; use of correct facemasks; social and physical distancing; self-isolation and quarantine if and when required. The shortage of facemasks for the community, and the frontline workforce, also became an is- sue, because people always expect to feel safe, whether at work, at home or when in the open community. Countless employers in conjunction with government recommendations also mandated that employees were terminated or went on 'leave without pay', which resulted in mass unemployment as many jobs were made redundant. The rationale for this strategy was to reduce transmission of the COVID-19 virus by decreasing social interaction, increasing social distancing and banning public overcrowding. Despite the fact that the first two levels of Maslow's Hierarchy, the physiological needs have been difficult to achieve, in respect to community compliance with COVID-19 safety guidelines, the third level appears to have been even more challenging, and problematic. Physical and social distancing issues relate directly to Maslow's third level need, belongingness and love. This was a testing situation for members of the community; since it often required people to maintain physical and social distancing from "loved-ones" in the family, extended family, friends and work colleagues. Cutting-edge technology however did provide virtual online contact with these same "loved ones", but, non-compliance issues with social distancing requests still prevailed as face to face and physical contact such as "a smile, a hug, a cuddle and a kiss" are also basic human needs. An interesting observation to consider is that when the first three foundation levels of Maslow's hierarchy of needs are compromised, Esteem and Self-actualization as motivational targets may become problematic and unachievable. During the COVID-19 pandemic, community esteem was challenged and tested. Despite requests and mandates generated by authorized government officials, with "lockdown" directives, movement control orders, "stay at home" requests, WFH appeals, and self-quarantine instructions; people continued to be non-compliant by going shopping, attending religious gatherings, going to work, participating in anti-lockdown demonstrations, ignoring social distancing rules. However, these breaches of non-compliance, almost certainly were associated with fear and anxiety, a lowered sense of self-esteem, guilt feelings from social judgment; negative thoughts and feelings related to remorse, and shame for their undesirable behavior. The final level being self-actualization would therefore be to some extent impossible to achieve in the circumstances related to non-compliance. However, many global communities and individuals have been very positive during the COVID-19 pandemic and complied with the safety rules and regulations. In doing so global communities have made the best out of a life-threatening situation, and seen "the light at the end of the tunnel". But many other members of the global commu- 
nity have found these unprecedented times extremely difficult to cope and have been unmotivated. Whatever the desire may have been for the individual, the motivation to ascend to the final level just wasn't there.

\section{Conclusion}

A positive outcome of the COVID-19 pandemic has been the opportunity for the worldwide community to consider human beings and their nature. Is it true that a person lives by bread alone? If true, what happens when there is no bread? What ensues to a person's motivation when there is plenty of bread and their stomach is full? Simultaneously "higher" needs transpire and these needs, dominate the human being. As soon as each of these needs is fulfilled, then new still "higher" need emerges. This is the concept where fundamental human needs are prearranged into a hierarchy of relative prepotency. We as human beings are motivated by a hierarchy of needs, which are structured into a hierarchy where fundamental needs must be more or less met, rather than all or nothing prior to pursuing higher needs. The order of needs is not rigid but instead may be flexible based on external circumstances or individual differences. Behaviors which are encouraged by motivation are simultaneously determined by more than one basic need [3].

\section{Bibliography}

1. Cohen J., et al. "Contributing factors to personal protective equipment shortages during the COVID-19 pandemic". Preventive Medicine (2020).

2. Donahue DA., et al. "The all needs approach to emergency response". Homel Security Affair 8.1 (2012): 1-17.

3. Maslow AH. "A theory of human motivation". Psychology Review 50.4 (1943): 370.

4. Taormina RJ and Gao JH. "Maslow and the motivation hierarchy: measuring satisfaction of the needs". American Journal of Psychology 126.2 (2013): 155-177.

5. Rapoza K. "Will a 10-week lockdown lead to a great depression?" Forbes (2020).

6. Chen N., et al. "Epidemiological and clinical characteristics of 99 cases of 2019 novel coronavirus pneumonia in Wuhan, China: a descriptive study". Lancet 395 (2020): 507-513.

7. Chin J. "The epidemiological characteristics of an outbreak of 2019 novel coronavirus diseases (COVID-19) in China". Chinese Journal of Epidemiology 41 (2020): 145-151.
8. World Health Organization. "Coronavirus disease 2019 (COVID-19): Situation report- 91” (2020b).

9. World Health Organization. "Rolling updates on coronavirus disease (COVID-19)" (2020a).

10. Scott S and Duncan CJ. "Biology of Plagues: Evidence from Historical Populations”. (Cambridge University Press (2001).

11. Bollet, AJ. "Plagues and Poxes: the impact of human history on epidemic disease". New York: Demos (2004).

12. Hays, JN. "Epidemics and Pandemics: their impacts on human history". Oxford: ABC-CLIO (2006).

13. CDC. "People who need to take extra precautions" (2019a).

14. Witte K and Allen M. "A meta-analysis of fear appeals: implications for effective public health campaigns". Health Education Behavior 27 (2000): 591-615.

15. “COVID-19: Protecting health-care workers". The Lancet 395 (10228): 922.

16. Clarke L. "Panic: myth or reality?" Contexts 1 (2002): 21-26.

17. Mobbs D., et al. "The ecology of human fear: survival optimization and the nervous system". Frontiers in Neuroscience 9 (2015): 55.

18. Cole S., et al. "Affective signals of threat increase perceived proximity". Psychology Science 24 (2013): 34-40.

19. Drury J. "The role of social identity processes in mass emergency behaviour: an integrative review". European Review of Social Psychology 29 (2018): 38-81.

20. Stiff C. "The game theory of panic-buying - and how to reduce it". The Conversation (2020).

21. Dickie R., et al. "The effects of perceived social norms on hand washing behavior in students". Psychology, Health and Medicine 23 (2018): 154-159.

22. Cialdini RB., et al. "A focus theory of normative conduct: a theoretical refinement and reevaluation of the role of norms in human behavior". in Advances in Experimental Social Psychology 24 (1991): 201-234.

23. Berkowitz AD. "An overview of the social norms approach. in Changing the Culture of College Drinking: A Socially Situated Health Communication Campaign". (eds. Stewart, L. \& Lederman, L. C.) 193-214 (Hampton Press, 2005). 
24. Abrams D., et al. "Knowing what to think by knowing who you are: self-categorization and the nature of norm formation, conformity and group polarization". British Journal of Social Psychology 29 (1990): 97-119.

25. Centola D. "An experimental study of homophily in the adoption of health behavior". Science 334 (2011): 1269-1272.

26. Christakis N A and Fowler J H. "Social contagion theory: examining dynamic social networks and human behavior". Statistics in Medicine 32 (2013): 556-577.

27. Christakis N A and Fowler J H. "Social network sensors for early detection of contagious outbreaks". PLoS One 5 (2010): e12948.

\section{Assets from publication with us}

- Prompt Acknowledgement after receiving the article

- Thorough Double blinded peer review

- Rapid Publication

- Issue of Publication Certificate

- High visibility of your Published work

Website: www.actascientific.com/

Submit Article: www.actascientific.com/submission.php

Email us: editor@actascientific.com

Contact us: +919182824667 